\title{
Magnetic nanobeads decorated by thermo-responsive PNIPAM shell as medical platforms for the efficient delivery of doxorubicin to tumour cells $\dagger$
}

\author{
Smriti R. Deka, $\uparrow^{a}$ Alessandra Quarta, $\uparrow^{a b}$ Riccardo Di Corato, ${ }^{b}$ Andreas Riedinger, ${ }^{a}$ Roberto Cingolani ${ }^{a}$ \\ and Teresa Pellegrino*ab
}

\author{
Received 6th August 2010, Accepted 22nd September 2010 \\ DOI: 10.1039/c0nr00570c
}

\begin{abstract}
Medical nanoplatforms based on clusters of superparamagnetic nanoparticles decorated with a PNIPAM thermo-responsive shell have been synthesized and used as drug carriers for doxorubicin (DOXO), a common chemotherapeutic agent. The nanosystem here developed has a total diameter below $200 \mathrm{~nm}$ and exploits the temperature responsive behaviour of the PNIPAM polymeric shell for the controlled loading and release of DOXO. The system has been tested in vitro on tumour cells and it clearly demonstrates the effectiveness of drug polymer encapsulation and time-dependent cell death induced by the doxorubicin release. Comparative cellular studies of the DOXO loaded nanoplatform in the presence or absence of an external magnet $(0.3 \mathrm{~T})$ showed the synergic effect of accumulation and enhanced toxicity of the system, when magnetically guided, resulting in the enhanced efficacy of the system.
\end{abstract}

\section{Introduction}

In the last decades, remarkable progress has been accomplished in the development of new polymer based functional materials, showing stimuli-responsive behavior. ${ }^{1-4}$ These "smart" polymers have found applications in different fields, including the pharmaceutical area. ${ }^{5,6}$ In this field, the design of "intelligent" drug delivery systems requires the preparation of carriers suitable for hosting, protecting, transporting the embedded drug and for controlling its release to the target site, under the action of a defined physical stimulus, such as the cellular $\mathrm{pH}$, the local temperature, or the tumor reducing environment.

On the other hand, the manipulation and the delivery of the nanocontainer and whatever it is associated to it, towards a selected area (a tumor or a damaged tissue) could be certainly enhanced and facilitated if superparamagnetic nanoparticles are included within the carrier systems. ${ }^{7}$ The system becomes magnetically active upon the application of an external magnet as it will accumulate to the site where the magnet is applied, while it will be re-dispersed in solution upon the removal of the magnet. Additionally, magnetic nanoparticles, exposed to appropriate radio frequencies, could generate heat that can be exploited for hyperthermia treatment to kill tumor cells in cancer therapy or provide the external stimulus, the local heat, necessary to open the nanocontainer and release the drug. ${ }^{8-10}$

\footnotetext{
a Istituto Italiano di Tecnologia, via Morego 30, 16163 Genova, Italy. E-mail: teresa.pellegrino@unisalento.it; Fax: +39 0832298 230; Tel: +390832298214

${ }^{b}$ National Nanotechnology Laboratory of CNR-NANO, via per Arnesano km 5, 73100 Lecce, Italy

$\dagger$ Electronic supplementary information (ESI) available: A table summarizing the DOXO loading parameters, DLS of some steps of the reaction and additional TEM characterization images of the DOXO loaded nanobeads, and additional TEM characterization of cells treated with the nanobeads. See DOI: $10.1039 / \mathrm{c} 0 \mathrm{nr} 00570 \mathrm{c}$

\$ These authors have contributed equally to this work.
}

It is then understandable while active research efforts are devoted to the combination of magnetic nanoparticles with stimuli-responsive polymers. Recently, we have reported on the exploitation of acidic pH-responsive nanogel as cargo for the controlled loading and release of $\mathrm{pH}$-mediated iron oxide nanoparticles (IONPs) and at the same time of short oligonucleotides (which could be the therapeutic agents in some genetherapy). ${ }^{11}$

Different groups have been working on the growth of thermoresponsive polymers on the surface of IONPs. ${ }^{7,12-17}$ Poly( $N$-isopropylacrylamide), PNIPAM for instance is a linear polymer that experiences a conformational change from a random coil to a collapsed state at a critical temperature, also known as lower critical solution temperature (LCST), which is equal to $32{ }^{\circ} \mathrm{C} .{ }^{18,19}$ In the case of the PNIPAM-shell on IONPs, it has been shown that the polymer transition from a coil to a shrinked state at the IONP surface promotes the inter-particle aggregation and consequently the aggregates reply faster to the magnet and can be easily separated. This behavior has been exploited to trigger the separation of individual magnetic nanoparticles from the solution phase, which is still difficult to be achieved. ${ }^{20,21}$

Indeed, nanocrystals of iron oxide with dimension of the order of $10 \mathrm{~nm}$ have a low magnetization per particle, and thus it is difficult to separate them from the solution or to control their movement in blood by using moderate magnetic fields. This limits their use in separation and drug delivery. Increasing the nanocrystal size increases the saturation magnetization, but also induces the superparamagnetic-ferromagnetic transition (at a domain size of $c a$. $30 \mathrm{~nm}$ for $\mathrm{Fe}_{3} \mathrm{O}_{4}$ ), so that nanocrystals are no longer dispersible in solution. ${ }^{22,23}$ The PNIPAM shell on top of IONPs proposed here proved to trigger in a controlled manner the nanoparticles aggregation, thus maintaining the colloidal stability of superparamagnetic nanoparticles when the temperature is kept below $32{ }^{\circ} \mathrm{C}^{20,24}$

The above mentioned superparamagnetic nanoparticles coated with PNIPAM have been also exploited for the drug 
encapsulation, ${ }^{25}$ however, the temperature-mediated interparticle aggregation might represent a problem for their exploitation as in vivo drug delivery carriers.

Recently, secondary structures of magnetic nanocrystals obtained by controlled clustering of magnetic nanocrystals have been proposed as a valuable alternative to individual IONPs with potential as drug carriers. The clustering of magnetic nanoparticles offers the advantage to increase the total magnetization of the system while retaining the superparamagnetic feature of the individual magnetic nanoparticles: the magnetic clusters can be easily dispersed in solution when the magnet is removed. However, their use as magnetic carriers for drug delivery requires a precise control of the size in order to obtain stable colloidal nanoclusters, (from now on referred to as nanobeads (NBs)) which are at the same time small enough to avoid RES (reticuloendothelial system) sequestration. ${ }^{26}$

In this frame, we have recently reported a procedure to cluster, in a controlled manner, surfactant coated magnetic nanoparticles by enwrapping several iron oxide nanoparticles within a polymer shell of poly(maleic anhydride-alt-1-octadecene) ${ }^{27}$ The procedure allows to precisely tune the size, the shape and the number of IONPs per bead and to modulate the magnetic response of the resulting nanobeads (NBs). In the present work, to engineer appropriate magnetically guided carriers we have first decorated the nanobead surface with an additional layer of a thermoresponsive polymer based on PNIPAM, then we have exploited this shell for the temperature-controlled loading and release of doxorubicin, a chemotherapeutic agent. The system was tested on tumour cells and these studies allow us to elucidate the main features of our magnetic temperature-responsive nanocarriers.

In this work we demonstrate that the concept of magnetic cluster-like beads embedded in a PNIPAM shell has a great potential in the drug delivery of chemotherapeutics to tumour cells.

\section{Results and discussion}

\section{Preparation of PNIPAM-NBs and their characterization}

The procedure for the synthesis of PNIPAM-NBs is illustrated in Scheme 1. By using a protocol recently reported by us, ${ }^{27}$ we first prepared clusters of iron oxide nanoparticles, the so called starting NBs, by enwrapping multiple iron oxide nanoparticles (6 $\mathrm{nm}$ in diameter) within an amphiphilic polymer named poly(maleic anhydride-alt-1-octadecene) (PC18). In order to grow the PNIPAM shell, the anhydride groups of the polymer at the bead surface could be further processed. For this purpose we first linked short priming ligands, the 2-aminoethylmethacrylate molecules (AEM) to the nanobead surface, the primary amino group of the AEM forms an amide bond with the anhydride group of the polymer. This step allows the introduction of $\mathrm{C}-\mathrm{C}$ double bonds at the nanobead surface, which are the moieties that in the next step initiate the NIPAM copolymerization at the bead surface.

More in detail, the addition of base (TEA) first deprotonated the AEM, which was subsequently added to the NBs in acetonitrile (ACN) under nitrogen atmosphere. After 24 hours, the modified NBs were precipitated by addition of petroleum ether, and re-dispersed in acetone. The polymerization of NIPAM on the surface of NBs was carried out in water-acetone mixture. To the AEM-NBs in acetone, the radical initiator (AIBN in acetone) was first added, followed by addition of deionized water and NIPAM monomers and the mixture stirred for 6 hours at $70{ }^{\circ} \mathrm{C}$ under nitrogen atmosphere.

At the end of the reaction the PNIPAM coated beads were at first magnetically separated and the excess of the NIPAM monomers was removed by few additional precipitation steps which allowed us to completely purify the PNIPAM-NBs from the NIPAM monomers left in the supernatant.

As shown in Fig. 1, while the starting NBs have an average diameter (determined by TEM) of $65 \pm 15 \mathrm{~nm}$, the final PNIPAM-NBs have a corresponding diameter of $135 \pm 22 \mathrm{~nm}$, and the PNIPAM-NBs samples (as well as the starting NBs) are well dispersed on the TEM grid giving a clear indication of the growth of the PNIPAM shell around each individual starting bead. The change in size due to the polymer growth is also confirmed by the change in hydrodynamic diameter of the PNIPAM-NBs $(286 \mathrm{~nm})$ with respect to the diameter of the starting NBs $(146 \mathrm{~nm}$ ) in PBS as measured by DLS (Fig. S2 $\uparrow$ ). (It is also worth to know that even for the intermediate product, the AEMmodified NBs, the TEM picture does not show any aggregation (data not shown) and the DLS diameter in acetone was of $189 \mathrm{~nm}$.)
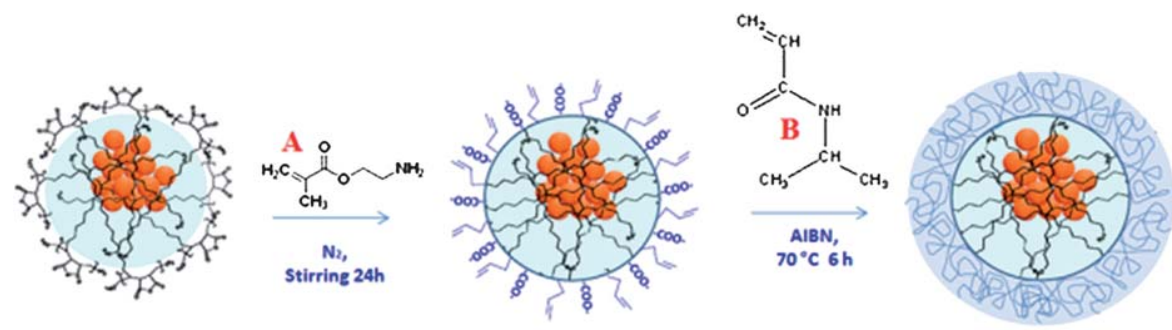

A: 2-aminomethylmethacrylate

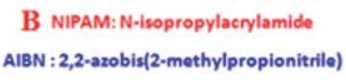

B NIPAM: N-isopropylacrylamide
AIBN : 2,2-azobis(2-methylpropionitrile)

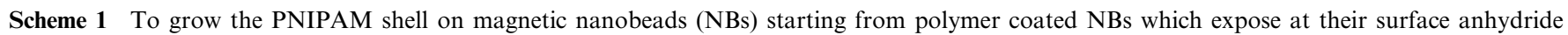

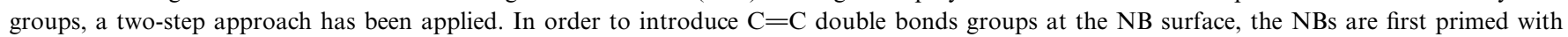

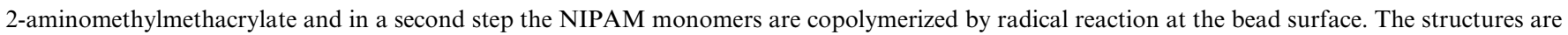
just cartoons which underline the functional groups at surface and do not correspond to the real molecular structures. 


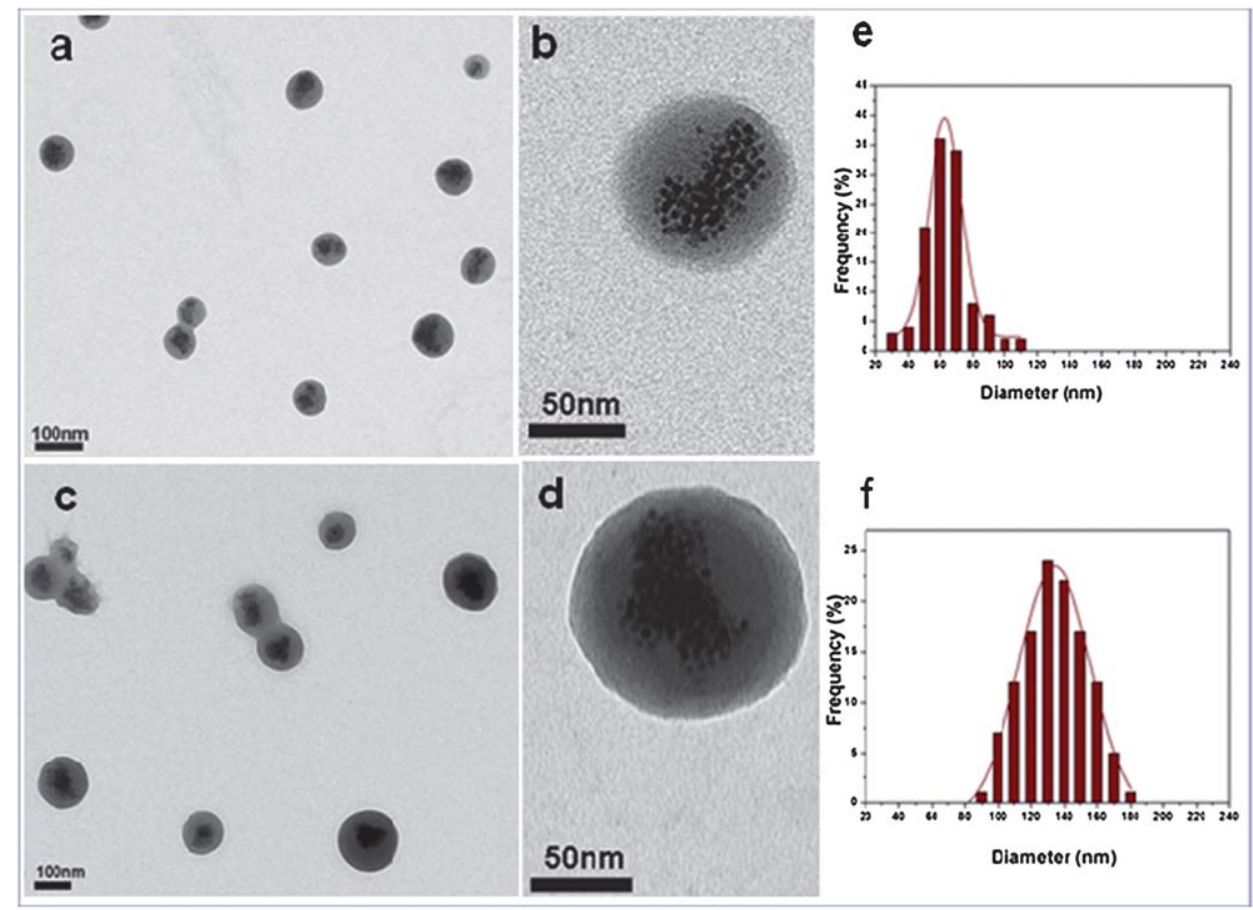

Fig. 1 TEM characterization of the starting NBs ( $a$ and b) and corresponding PNIPAM-NBs (c and d) at low field and at high magnification. The statistical TEM-diameter measured (f) for the PNIPAM-NBs corresponds to $135 \pm 22 \mathrm{~nm}$ and (e) for the starting NBs corresponds to $65 \pm 15 \mathrm{~nm}$. The statistics have been done on an average of 150 beads measured.

The thermo-responsive properties of the nanobeads before and after the PNIPAM coating provide evidences of the modification of the bead surface. Fig. 2 displays the hydrodynamic diameter of the nanobeads when the temperature was increased from 20 to $55^{\circ} \mathrm{C}$ (the heating curve) and vice versa when it was decreased from 55 to $20^{\circ} \mathrm{C}$ (the cooling curve) for the starting NBs (Fig. 2b) and for the PNIPAM-NBs in water (Fig. 2a), respectively.

The selected range of temperature allowed us to study the hydrodynamic size of the NBs above and below the LCST of the PNIPAM, which is, as reported for the linear PNIPAM polymer, around $32{ }^{\circ} \mathrm{C}$. As shown in Fig. 2a, for the PNIPAM-NBs we found a well-defined volume change observed at a temperature around $32^{\circ} \mathrm{C}$. The DLS diameter of the PNIPAM-NBs changes substantially from $286 \mathrm{~nm}$ at $20^{\circ} \mathrm{C}$ to $250 \mathrm{~nm}$ at $55^{\circ} \mathrm{C}$, due to the transition from the random coil to the collapse state of the PNIPAM chains when the temperature was increased above
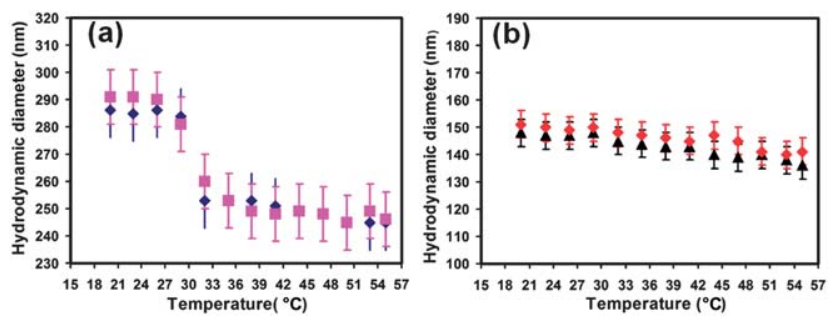

Fig. 2 Temperature dependence of hydrodynamic diameter for (a) PNIPAM-NBs (blue diamonds: temperature increased from 20 to 55 ${ }^{\circ} \mathrm{C}$ and violet squares: temperature decreased from 55 to $20^{\circ} \mathrm{C}$ ) and (b) starting NBs (black triangles: temperature increased from 20 to $55^{\circ} \mathrm{C}$ and red diamonds: temperature decreased from 55 to $20^{\circ} \mathrm{C}$ ).
$32{ }^{\circ} \mathrm{C}$. The reversibility of the transition was also observed, as indeed the heating and the cooling curves were found to be basically equal. In the case of starting NBs in water, the hydrodynamic diameter was almost constant at a diameter around $146 \mathrm{~nm}$ over the temperature range from 21 to $43{ }^{\circ} \mathrm{C}$ and no transition occurs at $32^{\circ} \mathrm{C}$ (Fig. 2b) while only a small variation of the DLS size of few nanometres was observed at temperature of $45^{\circ} \mathrm{C}$, which might be due to a slight contraction of the polymer PC18 of which the nanobeads are made occurring at this temperature. The same behavior was observed for the starting NBs in ACN, the solvent in which the nanobeads are prepared (in this case the mean diameter was averaged around $125 \mathrm{~nm}$, data not shown).

The temperature responsive results observed on our PNIPAM-NBs are in accordance with the findings of other groups that have grown the PNIPAM on other types of meso-micro templates (like silica beads or polymer beads). ${ }^{28-31} \mathrm{It}$ is important to point out that on meso-scale objects (100-200 nm), like our PNIPAM-NBs, the polymer contraction involves a change of the volume at individual PNIPAM-NB and it does not involve interparticle agglomeration. This behavior is obviously different from that of individual PNIPAM-coated IONPs in which the thermoresponsive behavior drives the inter-particle aggregation, leading to micrometre aggregates. The thermo-response behavior of our PNIPAM-NBs is definitely more advantageous when the system is designed for drug delivery as in vivo aggregation should always be avoided.

The encapsulation of NBs within the PNIPAM shell has been additionally confirmed by the FT-IR fingerprint spectra obtained when comparing the starting NBs, the AEM-NBs and the PNIPAM-NBs respectively (Fig. 3). In the IR spectrum of the 
(a)

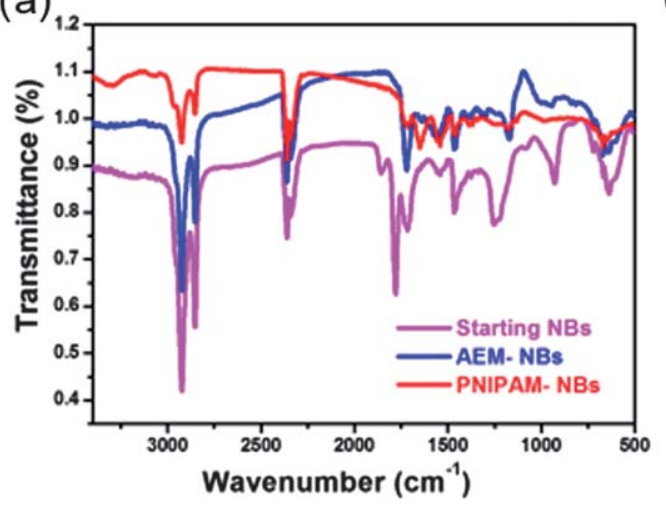

(b)

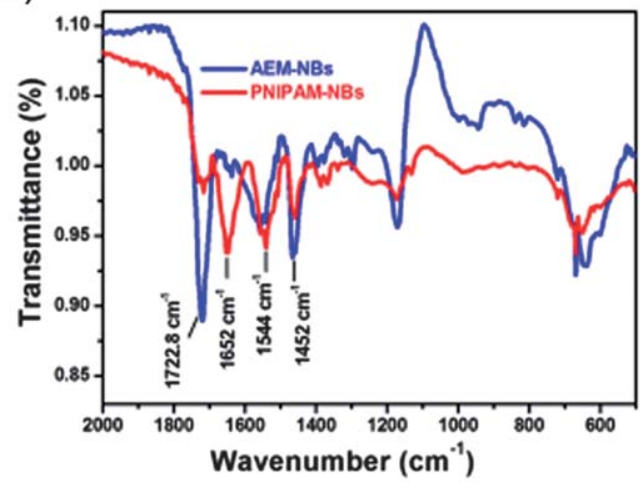

Fig. 3 (a) IR-spectra of starting NBs, AEM-modified NBs and PNIPAM-NBs. (b) Detailed IR-spectra of the region of interest for the PNIPAM growth for the AEM-modified beads and PNIPAM-NBs.

starting NBs, the peaks at $1780 \mathrm{~cm}^{-1}$ and $1755 \mathrm{~cm}^{-1}$ could be assigned to the $\mathrm{C}=\mathrm{O}$ stretching (asymmetric and symmetric) of the carbonyl groups of the anhydride. After modification with AEM, the carbonyl peak of the carboxylate (per each AEM reacted towards to an anhydride group one carboxylate is produced) was slightly shifted to $1723 \mathrm{~cm}^{-1}$. In addition, due to the formation of amide group, a small peak at $1645 \mathrm{~cm}^{-1}$, likely due to the stretching of amide I carbonyl group $(\mathrm{C}=\mathrm{O} / \mathrm{N}-\mathrm{H})$ and another at $1564 \mathrm{~cm}^{-1}$, due to formation of amide II (N-H bend/ $\mathrm{C}-\mathrm{H}$ stretch) were observed. After NIPAM polymerization at the bead surface the peaks at 1645 and $1564 \mathrm{~cm}^{-1}$ were shifted at 1652 and $1544 \mathrm{~cm}^{-1}$ still due to the carbonyl of the amide groups of PNIPAM. Also, the signal of the amide carbonyl peak at $1652 \mathrm{~cm}^{-1}$ after PNIPAM polymerization was much stronger than the AEM-modified NBs, since the ratio of amide groups per bead increased. On the contrary, the peak at $1723 \mathrm{~cm}^{-1}$ of the carbonyl of the carboxylate was much weaker as it is screened by the PNIPAM polymer shell.

Taken all together, the TEM data, the curves DLS diameter versus temperature and the FT-IR spectra provide clear evidence for the surface modification and the PNIPAM polymerization on the surface of the NBs.

\section{Loading of doxorubicin within PNIPAM-NBs and corresponding release experiments}

The thermo-responsive change in volume of the polymer shell can be exploited for both the loading and the release of drug molecules. At temperature of $20{ }^{\circ} \mathrm{C}$ the PNIPAM-NBs have a larger DLS diameter as the PMIPAM shell is present in a random coil. We exploit the enhanced permeability of the PNIPAM shell at $20^{\circ} \mathrm{C}$ to load the doxorubicin (DOXO): the amount of DOXO loaded inside the PNIPAM-NBs has been determined by the difference between a solution of DOXO at initial concentration and that of DOXO left in solution after having magnetically separated the PNIPAM-NBs as sketched in Fig. 4A and B (more details are available in the experimental parts). Thanks to the cumulative effect of several superparamagnetic nanoparticles clustered per beads, the DOXOloaded PNIPAM-NBs were easily accumulated to the magnet within 1 hour, making the separation protocol much easier and faster without the need of filtering or column purification protocols. In most of the loading experiments starting from a PNIPAM-NBs solution at $\mathrm{Fe} 50 \mu \mathrm{g} \mathrm{mL} \mathrm{m}^{-1}$ concentration, a DOXO solution of $67 \mu \mathrm{g} \mathrm{mL}^{-1}$ was added and in these conditions we could load within the PNIPAM shell a DOXO amount equal to $50.5 \pm 3.5 \mu \mathrm{g} \mathrm{mL}^{-1}$ (calculated on the average of 7 independent experiments), which corresponds to a loading efficiency of about $75 \%$ (actually the highest loading efficiency we could reach). The release profiles have been recorded by using these loading conditions. However, by tuning the initial amount of PNIPAM-NBs and DOXO mixed together, we could vary the loading efficiency. For instance, we kept constant the initial amount of $\mathrm{Fe}$ at $12.5 \mu \mathrm{g} \mathrm{mL}^{-1}$ and by adding an initial amount of DOXO of respectively $10,16.8$, or $100 \mu \mathrm{g} \mathrm{mL}^{-1}$ we could load within the PNIPAM-NBs respectively $6.5,12.5$ or $24 \mu \mathrm{g} \mathrm{mL} \mathrm{m}^{-1}$, which correspond to a loading efficiency respectively of 65,74 , and $25 \%$. (Those sample have been tested later on the tumor cells, however, see Table $\mathrm{S} 1 \dagger$ for the summary of the DOXO loading results obtained.) The loading of DOXO within the PNIPAM shell is also accompanied by an increase in the DLS diameters of the nanobeads from $286 \mathrm{~nm}$ for the PNIPAM-NBs to $310 \mathrm{~nm}$ for the DOXO-loaded PNIPAM-NBs, while no aggregations were shown on TEM image (Fig. S3†).

The release profile of DOXO from the PNIPAM-NBs was studied at $37^{\circ} \mathrm{C}$ in a PBS buffer solution at $\mathrm{pH} 7.4$ as for all the subsequent cell studies the cell cultures were kept at this temperature.

At temperature above the LCST, the PNIPAM shell becomes hydrophobic and leads to the collapse of the polymer layer and consequently allows the water soluble DOXO to diffuse out quickly from the polymer shell. We observed that after 6 hours almost $45 \%$ of the loaded DOXO was released, which reached $50 \%$ release after 24 hours and reached a percentage of DOXO release of $80 \%$ at least 72 hours after keeping the system at $37^{\circ} \mathrm{C}$. The maximum DOXO release percentage reached was around $85 \%$ after 110 hours at $37^{\circ} \mathrm{C}$. On the other hand, when keeping the DOXO-loaded PNIPAM-NBs sample at $4{ }^{\circ} \mathrm{C}$ for about 72 hours, only $4 \%$ of the DOXO encapsulated was released in solution. At $4{ }^{\circ} \mathrm{C}$, after 12 and 24 hours the amount of DOXO released was negligible. 


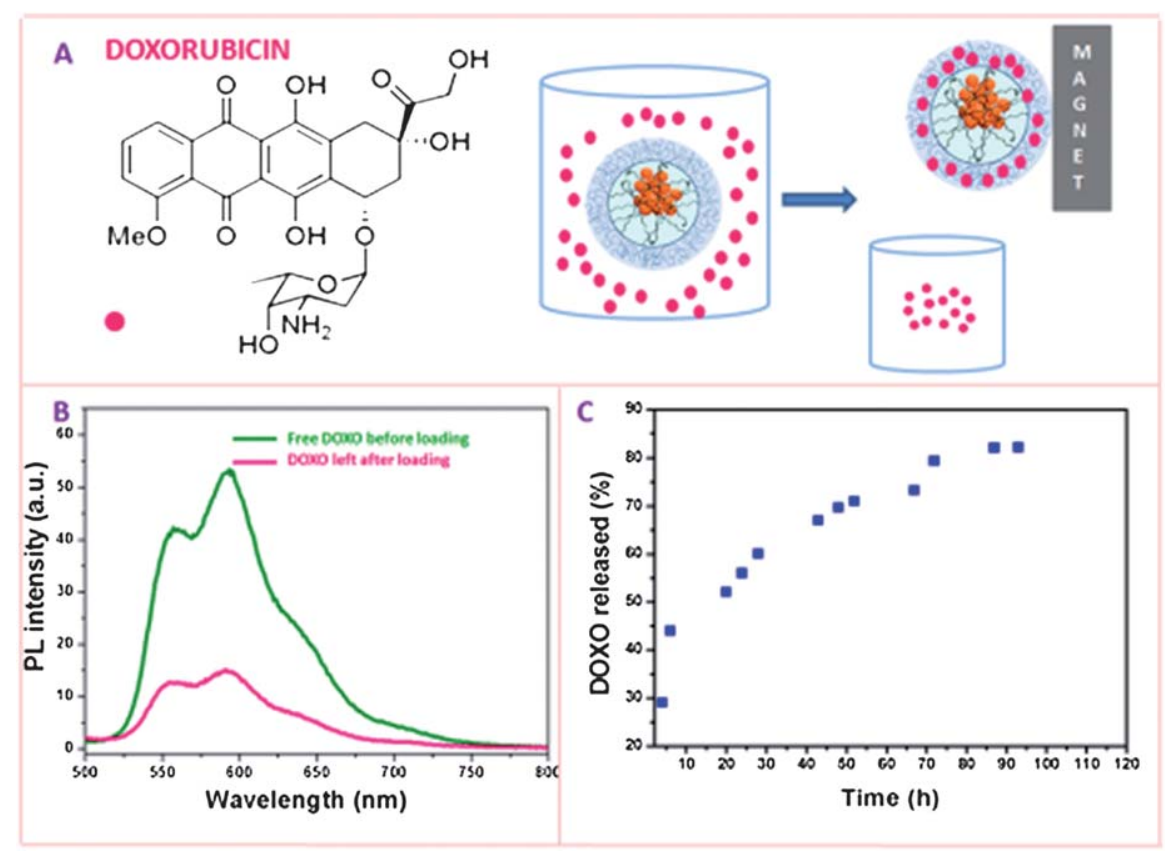

Fig. 4 (A) Chemical structure of Doxorubicin and cartoon sketching the loading of DOXO: after mixing the PNIPAM-NBs with DOXO at $20{ }^{\circ} \mathrm{C}$ for 12 hours, the DOXO-loaded PNIPAM-NBs are magnetically separated from the free DOXO left in solution. (B) The amount of DOXO loaded is measured by the difference in PL between a solution of DOXO at the same concentration of that mixed with the PNIPAM-NBs and the DOXO left in solution after having magnetically removed the beads. Fluorescence spectra of free DOXO (olive) and DOXO left (pink) in solution after loading experiment. (C) DOXO release kinetics in PBS at $37^{\circ} \mathrm{C}$ for the DOXO loaded PNIPAM beads.

\section{Drug release experiments from DOXO-loaded PNIPAM-NBs on tumor cell lineage}

To assess the drug delivery potential of the DOXO-loaded PNIPAM-NBs and the anticancer activity of the released $\mathrm{DOXO}$, in vitro cytotoxicity assays were performed. Tumor KB cells were incubated with the DOXO-loaded carriers at different time courses (24, 48 and $72 \mathrm{~h}$ ) and at different concentrations of Fe/DOXO administered (1.25/1.25, 2.5/2.5 and 5/5 $\left.\mu \mathrm{g} \mathrm{mL}^{-1}\right)$ (Fig. 5). The experiments were carried out both without (Fig. 5a) and with (Fig. 5b) the application of a small magnet $(0.3 \mathrm{~T})$ placed beneath the cell plates and the toxicity behavior was measured by a cell viability MTT assay for respectively, starting NBs, empty PNIPAM-NBs and DOXO-loaded PNIPAM-NBs and was compared to that of free DOXO administered directly to the cell media. In the absence of a magnet (Fig. 5a) it is evident that for the different time points tested and for most of the concentrations of the NBs employed, both the starting NBs and the PNIPAM-NBs showed cell mortality below 20\%, which provides an indication for the low toxicity profile of the carriers themselves (actually in those cases, the cells after showing an acute toxicity at $24 \mathrm{~h}$, had the time to recover after 48 and $72 \mathrm{~h}$ ). Those findings are in accordance with the data reported by Vihola et al. on bare PNIPAM polymer molecules tested on two different cell lines; a negligible toxicity of the PNIPAM polymer itself has been shown in their study. ${ }^{32}$

More significant is the comparison of the toxicity observed at 24 hours between the DOXO-loaded PNIPAM-NBs and that of free DOXO administered to the cells for the three concentrations tested. The encapsulation of the DOXO within the PNIPAM shell retards the toxic effect of DOXO on the cells as observed from the comparison of cell viability at the time point of 24 hours (for instance for Fe/DOXO 1.25/1.25 it corresponds to a cell survival of respectively $50 \%$ for the DOXO-loaded PNIPAMNBs against the $25 \%$ of the free DOXO, and the trend is the same also for the other Fe/DOXO ratios). On the contrary, the long term toxicity, measured at the time points of 48 and 72 hours, for the DOXO-loaded PNIPAM-NBs tend to reach a cell viability value that is comparable with that of free DOXO, confirming the continuous time release of DOXO from the PNIPAM shell on longer time scale.

It should be noticed that the DOXO release profile on the system itself, reported in Fig. 4, well accounts for the trend observed on the cells, since the curve almost reached the release saturation when the sample was kept at $37^{\circ} \mathrm{C}$ for a period longer than 3 days, while after $24 \mathrm{~h}$ only $50 \%$ of DOXO was released.

Importantly, the presence of a static magnet placed beneath the Petri dish should trigger the intracellular uptake of the beads due to the magnetic attraction of the magnetic NBs towards the magnet, thus favoring the amount of beads in contact with the cell membrane and consequently up-taken by the cells. ${ }^{27}$ Indeed, this trend is confirmed by the experimental data (Fig. 5b); the presence of the magnet induces an appreciable increase of the cytotoxicity compared to the corresponding samples incubated without magnet for all the Fe/DOXO concentrations tested. For instance, the viability of cells doped with DOXO-loaded PNIPAM beads at Fe/DOXO concentration equal to $1.25 \mu \mathrm{g} \mathrm{mL}^{-1}$ after $24 \mathrm{~h}$ is $40 \%$ when the incubation occurred with the magnet, while it corresponds to $50 \%$ without the magnet. One should be aware that in those experiments, it is not possible to discriminate the toxicity due to the DOXO release from extracellular nanobeads (even the DOXO released from non-internalized carriers in the cell medium could cross the cell membrane and enter the 


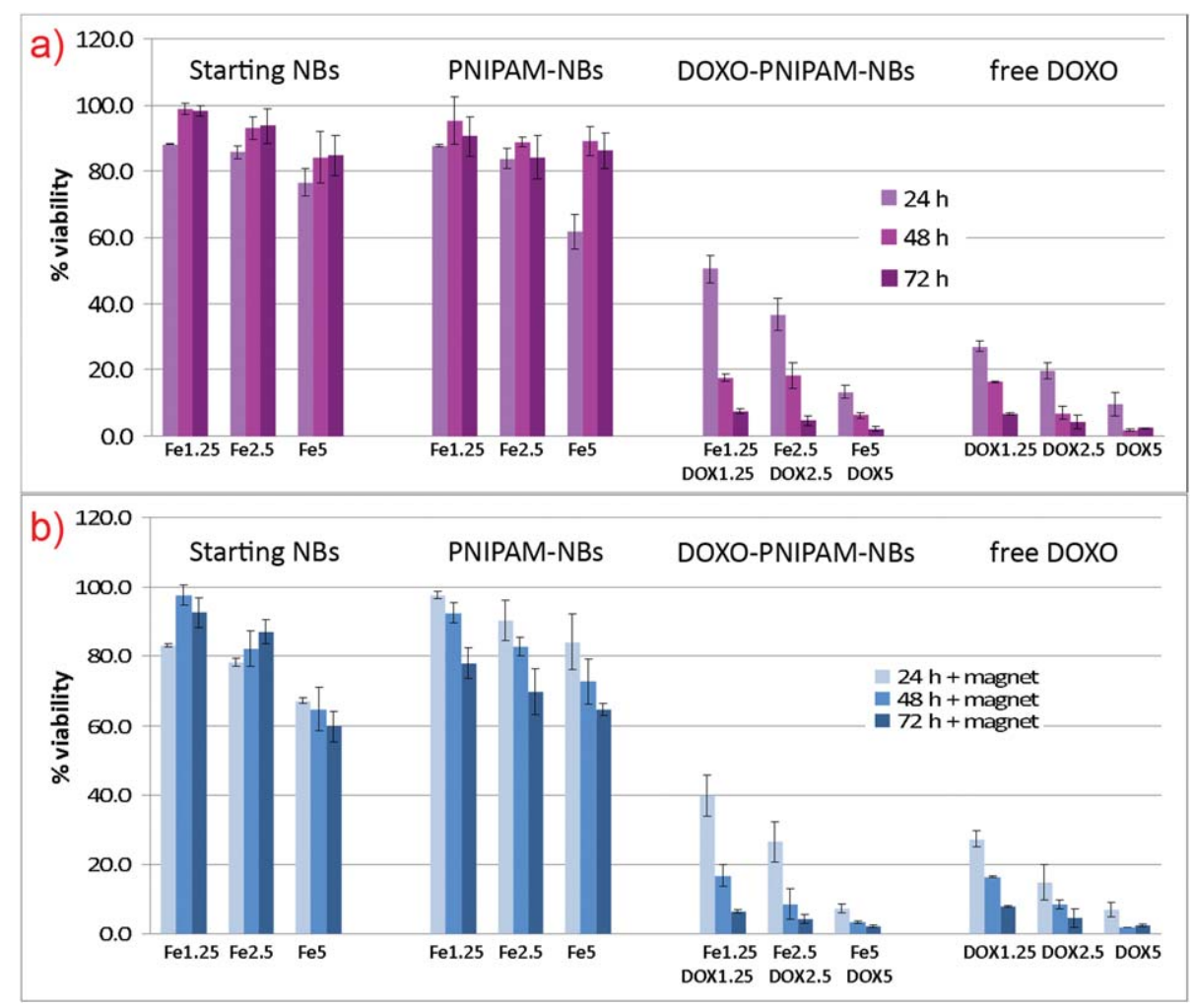

Fig. 5 In vitro cytotoxicity assay of PNIPAM-NBs loaded with DOXO performed (a) without and (b) with the application of an external magnet. KB cells were incubated for 24,48 and $72 \mathrm{~h}$ at $37^{\circ} \mathrm{C}$ with the loaded systems at different amounts of beads $\left(1.25,2.5 \mathrm{and} 5 \mu \mathrm{g} \mathrm{mL} \mathrm{m}^{-1}\right.$ of Fe) and DOXO (1.25, 2.5 and $5 \mu \mathrm{g} \mathrm{mL}^{-1}$ ). The cytotoxicity of the starting beads, of the empty PNIPAM-NBs and of the free DOXO has been also tested and compared to that of DOXO-loaded PNIPAM-NBs.

nuclei, as well). Such effect, however, should occur in the same manner in both samples with and without the magnet (to discriminate such effect a different thermo-responsive polymer with a shrinking temperature over $37{ }^{\circ} \mathrm{C}$ is required). The magnetic contribution to the cytotoxicity enhancement is more pronounced for short incubation times (at $24 \mathrm{~h}$ ), while after longer time, at 48 and $72 \mathrm{~h}$, the DOXO release effect prevails more than the accumulation effect (an amount of DOXO enough to kill the tumor cells has been released even without the application of the magnet).

To test the effect on the cell mortality when different amounts of DOXO have been encapsulated within the beads, KB cells were administered with PNIPAM-NBs $\left(\mathrm{Fe} 1.25 \mu \mathrm{g} \mathrm{mL}^{-1}\right.$, this nanobead concentration corresponds to the most negligible toxicity of the system itself) loaded with different amounts of DOXO, respectively $0.65,1.25$ and $2.5 \mu \mathrm{g} \mathrm{mL}^{-1}$. (Fig. 6). As expected, lower DOXO concentration corresponds to higher viability at $24 \mathrm{~h}$, although after $72 \mathrm{~h}$ more than $80 \%$ cells were found dead. On the other hand, when the cells were incubated with $2.5 \mu \mathrm{g} \mathrm{mL}^{-1} \mathrm{DOXO}$, after $24 \mathrm{~h}$ around $50 \%$ of cytotoxicity was recorded. These data also imply that a very low amount of drug (less than $1 \mu \mathrm{g} \mathrm{mL}^{-1}$ ) is needed to exert a high cytotoxic effect, on a longer time scale of $72 \mathrm{~h}$. All these features could make this carrier system a powerful tool for in vivo chemotherapy against cancer, where it is fundamental that the drug is active not immediately, after the intra body injection, but only after the tumor site has been reached. ${ }^{33,34}$ Also, lower drug amount needs to be administered to get complete tumor regression while minimizing the risk to develop chemoresistance. ${ }^{35-37}$

Although it is not straightforward to compare our results with those obtained by other groups (as indeed different groups have used different ways to estimate the amount of iron oxide based nanostructures administered to the cells in their studies, ${ }^{25,38}$ ) it is remarkable to mention that in our experiments we deliver

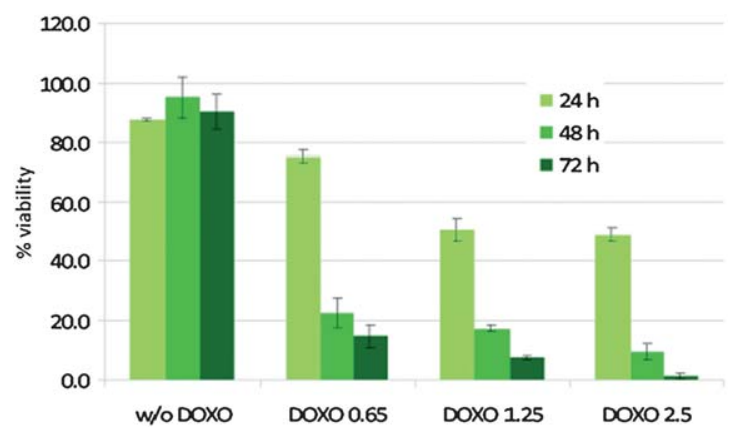

Fig. 6 Comparative cell viability assay of $\mathrm{KB}$ cells incubated with DOXO-loaded PNIPAM-NBs by keeping constant the amount of NBs $\left(1.25 \mu \mathrm{g} \mathrm{mL}^{-1} \mathrm{Fe}\right)$ and increasing the amount of DOXO loaded within the PNIPAM shell (respectively, $0.65,1.25$ and $2.5 \mu \mathrm{g} \mathrm{mL}^{-1}$ ). The cytotoxicity of the empty PNIPAM beads is also reported. For each sample the toxicity has been measured after an incubation time of respectively 24,48 and 72 hours, at $37^{\circ} \mathrm{C}$. 
a DOXO concentration in the same range used by other groups, ${ }^{38-41}$ however, by employing an amount of nanostructures (measured in terms of iron), lower with respect to that of other groups ${ }^{41,42}$ (to give an example the highest amount of iron of $5 \mu \mathrm{g}$ $\mathrm{mL}^{-1}$ used in this work corresponds to an amount of iron oxide nanoparticles of $6 \mathrm{~nm}$ in diameter of about $20 \mathrm{nM}$ ).

In order to correlate the toxicity data with the up-taking of the nanobeads, the intracellular amount of PNIPAM-NBs and starting NBs in terms of intracellular Fe amount was measured by means of elemental analysis (Fig. 7 and Table S2, ESI $\dagger$ ).

It is clear that either with or without the magnet the PNIPAMNBs were internalized by the KB cells more efficiently than the starting NBs (Fig. 7). Since the surface of both samples lacks any cellular addressing ligand or recognition molecule that could promote the interaction with the cell membrane and the internalization, this behavior can be attributed to the different surface charge and structure displayed by the two samples: according to the $\zeta$-potential measurements, PNIPAM-NBs are less negatively charged compared to the starting beads $(-10 \mathrm{mV}$ and $-40 \mathrm{mV}$, respectively, in PBS) and indeed the reduced repulsion at the negative cell membranes facilitates the uptaking. ${ }^{43}$ In the case of the PNIPAM-NBs some of the carboxyl moieties present at the starting NB surface are used in the reaction with the AEM priming molecules for the PNIPAM growth and thus do not contribute to the final negative surface charge of the carriers. Additionally, as also mentioned by others when PNIPAM-gold nanostructures have been studied, ${ }^{44}$ the up-taking might be driven by the hydrophobic interactions between the cell membrane and the PNIPAM polymer. At $37{ }^{\circ} \mathrm{C}$, i.e. over the LCST, the PNIPAM polymer is in the collapsed and hydrophobic conformation; indeed the interaction with the phospholipid part of the membrane could preferentially occur, thus enhancing the PNIPAM-NBs up-taking with respect to the starting NBs.

In addition the higher cytotoxicity of the PNIPAM-NBs with respect to the starting NBs, is confirmed by the observation that the presence of the magnet considerably increases the internalization of the PNIPAM-NBs: after 72 hours the intracellular Fe amount found was $2.5 \mu \mathrm{g} \mathrm{mL} \mathrm{m}^{-1}$, equivalent to the amount of

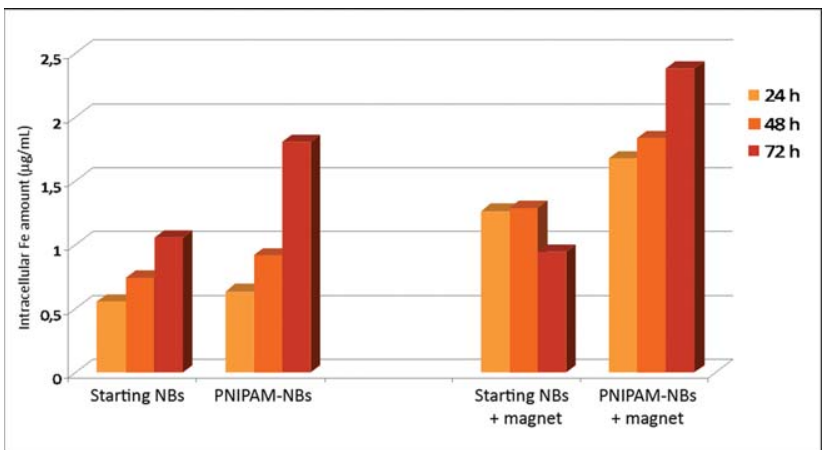

Fig. 7 Intracellular amount of $\mathrm{Fe}$ content $\left(\mu \mathrm{g} \mathrm{mL}^{-1}\right)$ for cells treated with starting beads and PNIPAM coated beads at an extracellular concentration of $2.5 \mu \mathrm{g} \mathrm{mL}^{-1}$. $100000 \mathrm{~KB}$ cells were incubated for 24,48 and 72 hours at $37^{\circ} \mathrm{C}$ with and without the application of an external magnet. After the incubation time the cells were digested and the $\mathrm{Fe}$ content was determined by elemental analysis.
PNIPAM-NBs externally administered to the cells. We conclude that the less negative surface provided by the PNIPAM shell to the beads, together with the magnetic manipulation of the inner core of the PNIPAM-NB system account for the efficient uptaking of the system developed in this work: after 72 hours nearly $100 \%$ of the PNIPAM-NBs administered to the cells was taken up by the cells, when the magnet was placed beneath the cell dish (Fig. 7). In Fig. 7 one should also notice that in general for all the samples the up-taking increases with time. This trend, however, is not maintained for the starting NBs after 72 hours in the presence of the magnet. This behavior might be attributed to the reduced stability of the starting NBs that tend to aggregate and stick to the cell plate due to the magnetic attraction resulting in a lower number of beads present in solution.

The cellular internalization of both starting NBs and PNIPAM-NBs was also visually monitored by TEM characterization of cells incubated with both starting NBs and PNIPAM-NBs samples. Fig. 8 shows the intracellular localization of the starting beads after $24 \mathrm{~h}$ incubation. Early and late endosomes (Fig. 8b) were present in the same cell: the early endosomes were quite large, displayed an irregular shape and contained a considerable amount of beads. On the other hand, late endosome and endolysosomal compartments were evident even after 48 h (Fig. S5 $†$ ): single iron oxide nanoparticles were held inside the lysosomes suggesting that the $\mathrm{pH}$ conditions of the lysosomes could degrade the polymer layer. However, further studies on longer time scale need to be carried out in order to explain these findings.

Even PNIPAM-NBs were phagocyted and retained into the endosomal compartments after $24 \mathrm{~h}$ (Fig. 9a). Fig. 9b shows the last stage of the membrane invagination during the formation of an early endosome. Even from the structural morphology of the beads uptaken within the cells it is possible to recognize the PNIPAM-NBs as indeed in this case the polymer layer is much thicker with respect to the starting NBs. Also in this case, from a qualitative point of view, after $48 \mathrm{~h}$ the cells were enriched with PNIPAM vesicles (Fig. S6 $\dagger$ ) and after 3 days the cells appeared overflowing (Fig. S6 $\dagger$ ). Those TEM images, tough qualitatively, confirm the above reported trend of preferential up-taking by the cells of the PNIPAM-NBs with respect to the starting NBs (Fig. S6†).

KB cells once incubated with DOXO-loaded PNIPAM-NBs (2.5/2.5 $\mu \mathrm{g} \mathrm{mL}^{-1} \mathrm{Fe} / \mathrm{DOXO}$ concentration) were imaged at different time delays of 2, 7 and $15 \mathrm{~h}$ incubation (Fig. 10a-c). The

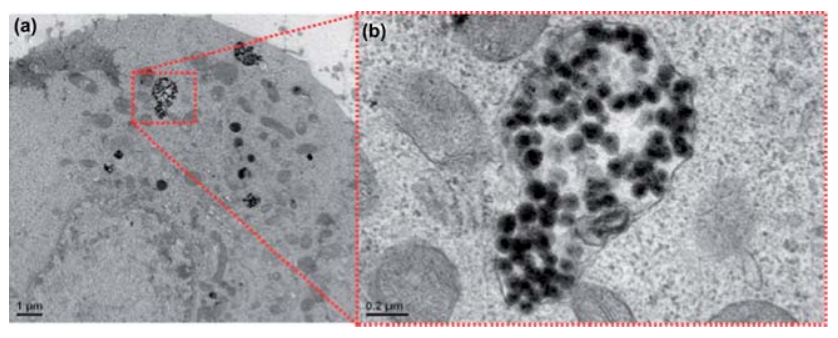

Fig. 8 TEM images of KB cells incubated with the starting NBs (a) after $24 \mathrm{~h}$ at $37^{\circ} \mathrm{C}$. (b) Higher magnification of a portion of the same image showing an endosome containing a considerable amount of nanobeads, many nanostructures having an inner dark core corresponding to IONPs and a lighter polymer shell are well distinguishable within the endosome. 


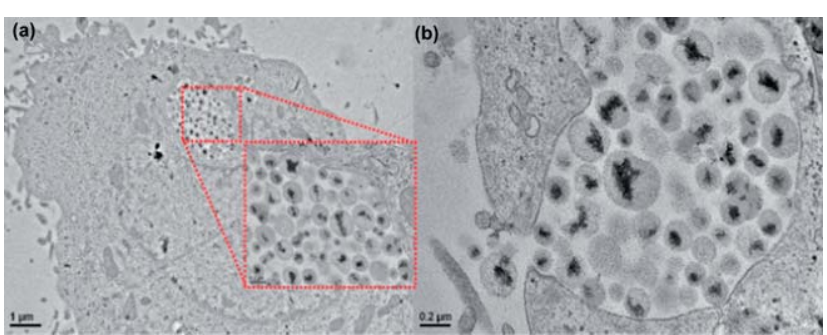

Fig. 9 TEM images of KB cells incubated with the PNIPAM beads after $24 \mathrm{~h}$ at $37^{\circ} \mathrm{C}$. Low magnification image showing the PNIPAM-NBs uptaken by the cell and accumulated in the endosome (see the inset). (b) Invagination of the cell membrane and formation of the endosome containing the PNIPAM-NBs.
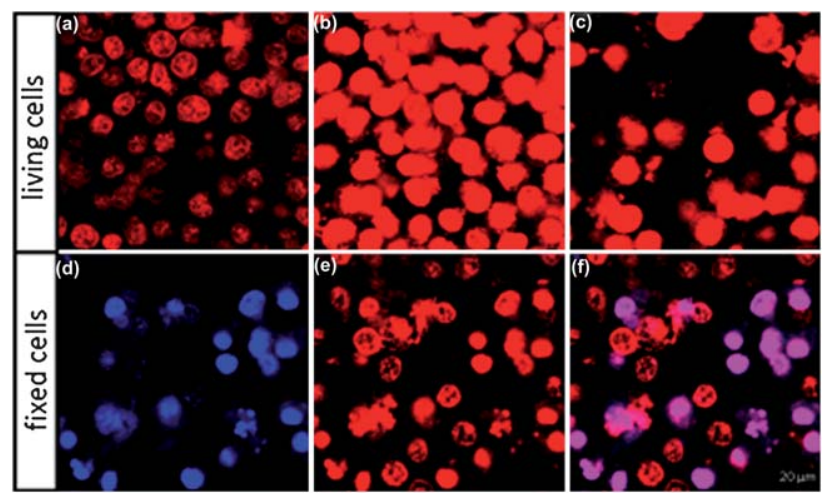

Fig. 10 (a-c) Confocal images of living KB cells exposed to PNIPAMNBs loaded with DOXO. Images were acquired after 2 (a), 7 (b) and $15 \mathrm{~h}$ (c) incubation time. (d-f) Confocal images of fixed cells treated with PNIPAM-NBs. The DAPI stains in blue the nuclei, while the red signal visualizes the DOXO (e) and the merged channel (f) allows the better visualization of dead cells, the violet spots.

fluorescent signal of DOXO allowed us to follow the time dependent DOXO internalization. After $2 \mathrm{~h}$, a red fluorescent signal of DOXO was recorded on cells, which significantly increased with time despite the number of cells in the recorded area after $15 \mathrm{~h}$ was less than that recorded after $7 \mathrm{~h}$ (most likely because the cells killed by the DOXO release were detached from the substrate). These data were also confirmed by looking at fixed cells after $15 \mathrm{~h}$. In Fig. 10d-f it is possible to distinguish between the necrotic cells and those that had up-taken DOXO without being killed: the blue fluorescent signal of nuclei staining with DAPI for the necrotic cells (Fig. 10d) is merged with the red fluorescent signal of DOXO (Fig. 10e) resulting in a final violet color in the merged images (Fig. 10d).

\section{Conclusion}

In this work, starting from magnetic nanobeads consisting of multiple iron oxide nanoparticles clustered together through a polymer, we have added a thermo-sensitive shell based on PNIPAM and we have exploited the PNIPAM-NBs as carriers for the doxorubicin.

The nanostructures here developed as drug carrier represent a second generation of multifunctional nano-materials based on multiple iron oxide nanoparticles which combine the benefit to have a stronger magnetic core, and thus a stronger response to the external magnet, with the advantage to keep the superparamagnetic behavior of the nanoparticles and thus easily to be dispersed in solution whenever the magnet is removed. In addition, the DOXO encapsulation within the PNIPAM shell allows to protect the external environment (the healthy tissues) from the toxic drug and also to slowly release the embedded drug. The DOXO released by the nanostructure exhibits pharmacological activity on tumor cells, and the drug release profile is clearly temperature and time dependent. Also, in concomitance to the physical force exerted by the static magnet by properly adjusting the incubation time, and the surface charge of the carrier nearly $100 \%$ cellular up-taking efficiency was achieved.

All these performances have been achieved in a miniaturized nanostructure, which has a final diameter still below the critical threshold (below $200 \mathrm{~nm}$ ) for applications in vivo and with a control on the overall morphology and thus functionality.

While in this work we provide the proof of concept for the use of magnetic beads decorated by PNIPAM as thermo-responsive polymer with a LCST of about $32{ }^{\circ} \mathrm{C}$, we could envision that by appropriate selection of the comonomer units (such as for instance a combination of NIPAM-co-acrylic acid-co-ethyl methacrylate) ${ }^{45-47}$ the transition temperature of the polymer could be switched to higher temperature (around $40-43^{\circ} \mathrm{C}$ ). The resulting thermo-responsive polymer magnetic nanobeads, could be used as carrier to release the drug at temperature higher than $37^{\circ} \mathrm{C}$, the physiological body temperature. The heat produced by the magnetic nanoparticles under appropriate alternating magnetic field might be used to damage the cancer cells by hyperthermia and at the same time to trigger the drug release. By using such system the "aspecific" drug release could be prevented. The magnetic heat-ability of MNPs might be exploited not only to induce hyperthermia, but the same thermal effect produced by the magnetic nanoparticles might be exploitable to trigger the conformation transition of the thermo-responsive polymer and thus the subsequent drug release. The work done in this study poses the base for the development of such multifunctional nanostructures.

\section{Materials and methods}

\section{Chemicals}

$N$-Isopropylacrylamide (NIPAM, 97\%), 2,2'-azobis(2-methylpropionitrile) (AIBN), 2-aminoethyl methacrylate hydrochloride (AEM), triethylamine, (TEA, 99\%), poly(maleic anhydride-alt-1octadecene) $M_{\mathrm{n}} 30000-50000$ (PC18), and doxorubicin hydrochloride (DOXO) were supplied by Sigma Aldrich and were used without any further purification. Solvents like acetonitrile (ACN, HPLC grade), tetrahydrofuran (THF), petroleum ether, and acetone were supplied by Carlo Erba.

\section{Synthesis of nanobeads (NBs)}

To prepare magnetic nanobeads, in a $4 \mathrm{~mL}$ glass vial, $50 \mu \mathrm{L}$ of IONPs $(15.4 \mu \mathrm{M}$ nanoparticle concentration, $\mathrm{d}=6 \mathrm{~nm})$ in toluene were dried to remove toluene completely and the nanoparticles were redissolved in $150 \mu \mathrm{L}$ of THF. Soon after, we added $50 \mu \mathrm{L}$ of a stock solution of Poly(maleic anhydride-alt-1octadecene) (PC18) in THF (50 mM, this concentration refers to 
the polymer monomer units). The mixture was shaken at $1000 \mathrm{rpm}$ at $20{ }^{\circ} \mathrm{C}$ for 60 minutes. Subsequently, $800 \mu \mathrm{L}$ of acetonitrile $(\mathrm{ACN})$ were added at a flow rate of $250 \mu \mathrm{L} \mathrm{min}{ }^{-1}$. In order to improve size distribution, after the beads were formed, a magnet $(0.3 \mathrm{~T})$ was placed to one side of the vial and the first portion attracted to the magnet (within the first $10 \mathrm{~min}$ ) was discarded. To the recovered supernatant, the magnet was applied to the glass wall for 12 hours, in order to quantitatively recover to the magnet all the beads left in solution. To scale up the beads production, the procedure reported was repeated 10 times and the beads recovered to the magnet, from each batch, were then redissolved in fresh $\mathrm{ACN}$ to a concentration of nanobeads corresponding to $655 \mu \mathrm{g} \mathrm{mL} \mathrm{mL}^{-1}$ of $\mathrm{Fe}$, as determined by elemental analysis. Those starting NBs in ACN are used for the next step of PNIPAM growth. For the comparative behavior of the starting NBs with the PNIPAM-NBs, the magnetic NBs prepared in ACN were simply transferred in water, for the cell study by attracting them to magnet, removing the $\mathrm{ACN}$ and adding fresh PBS buffer ( $\mathrm{pH}$ 7.4). Also in this case, the nanobeads concentration was always referred as Fe content $\left(\mu \mathrm{g} \mathrm{mL}{ }^{-1}\right)$ and it was determined by elemental analysis.

\section{Functionalization of nanobeads with 2-aminoethyl methacrylate (AEM-NBs)}

To prime the nanobead surface with 2-aminoethylmethacrylate in a $25 \mathrm{~mL}$ three-necked round-bottom flask, to $0.009 \mathrm{~g}$ of AEM, $1 \mathrm{~mL}$ of a solution of TEA in ACN ( $2 \mathrm{M})$ was first added. Then $2 \mathrm{~mL}$ of a NBs solution in ACN at $655 \mu \mathrm{g} \mathrm{mL}^{-1}$ of Fe were also added and the reaction volume was adjusted to $15 \mathrm{~mL}$ with ACN. The solution was left under stirring for 24 hours at $18^{\circ} \mathrm{C}$ in nitrogen atmosphere. Finally, $10 \mathrm{~mL}$ of petroleum ether were added to the reaction mixture in order to precipitate the modified $\mathrm{NBs}$, followed by re-dispersion in $\mathrm{ACN}$ and magnetic separation (as described above). In order to be sure to remove the excess of AEM the purification step was repeated twice. At the last step the modified NBs were dispersed in acetone at a concentration of $377 \mu \mathrm{g} \mathrm{mL}^{-1}$ of $\mathrm{Fe}$ (as determined by ICP).

\section{Polymerization of NIPAM on the surface of NBs (PNIPAM-NBs)}

To initiate polymerization of NIPAM at the bead surface, in a three-necked round-bottom flask, $0.006 \mathrm{~g}$ of AIBN was dissolved in $10 \mathrm{~mL}$ of acetone, and $2 \mathrm{~mL}$ of AEM-modified NB solution $\left(377 \mu \mathrm{g} \mathrm{mL}^{-1} \mathrm{Fe}\right)$ were added. Then, $0.2 \mathrm{~g}(1.76 \mathrm{mmol})$ of NIPAM and $20 \mathrm{~mL}$ of water were added. The reaction vessels were connected to a reflux condenser and purged with nitrogen for 30 minutes. The mixture was heated to $70{ }^{\circ} \mathrm{C}$ and the reaction was allowed to proceed for 6 hours under nitrogen atmosphere. The final product was collected by magnetic separation and was easily re-dispersed in deionized water. To remove the excess of monomers, the product was centrifuged at $4000 \mathrm{rpm}$ for 30 minutes and the precipitate was redissolved in water. This process was repeated three times.

\section{Doxorubicin loading experiment}

In order to load DOXO within PNIPAM-NBs $100 \mu \mathrm{L}$ of a solution of DOXO in water $\left(1 \mathrm{mg} \mathrm{mL} \mathrm{mL}^{-1}\right)$ were added to $1.4 \mathrm{~mL}$ of
PNIPAM-NBs in water (Fe concentration $50 \mu \mathrm{g} \mathrm{mL}^{-1}$ ) and the mixture was shaken overnight in the dark at $20^{\circ} \mathrm{C}$. The solution was then centrifuged at $4000 \mathrm{rpm}$, and the precipitate was redissolved in water $(1.5 \mathrm{~mL})$ and kept near the magnet for 1 additional hour, in order to collect the PNIPAM-NBs at the magnet and discard the free DOXO in solution. This step was repeated twice in order to remove completely the free DOXO in solution.

The amount of DOXO loaded inside the beads was determined by photoluminescence measurements, given as the difference between a solution of DOXO at the initial concentration used for the experiment and that of DOXO left in solution (in the supernatant) after the loading time. The DOXO has a maximum of emission at $591 \mathrm{~nm}$ when excited at $450 \mathrm{~nm}$. The amount of DOXO left in the supernatant was measured by a calibration PL curve obtained by plotting the PL intensity at $591 \mathrm{~nm}$ versus the DOXO concentration of standard solutions. Importantly, as the PL signal of DOXO changes over time, we have always prepared a DOXO solution at the same initial concentration $\left(67 \mu \mathrm{g} \mathrm{mL}^{-1}\right)$ of that added to the PNIPAM-NBs and we kept this solution in the same conditions (overnight at $20{ }^{\circ} \mathrm{C}$ in the dark) of those under which are kept the samples. This DOXO solution was used as stock solution for the preparation of all the standards at known concentration.

The drug loading efficiency was calculated as follows:

Encapsulation efficiency $(\%)=100 \times(($ initial amount of DOXO - amount of DOXO left in the supernatant)/initial amount of DOXO)

\section{DOXO release experiment from the DOXO-loaded PNIPAM-NBs}

We have followed the DOXO release by optical absorption (the DOXO has a maximum peak of adsorption at a wavelength of $483 \mathrm{~nm})$. In a glass vial, $2 \mathrm{~mL}$ of DOXO-PNIPAM-NB $(50 \mu \mathrm{g}$ $\mathrm{mL}^{-1} \mathrm{Fe}$ ) solutions in PBS were shaken gently at $37^{\circ} \mathrm{C}$. After a time lapse (data points were collected at different times respectively: 4, 6, 20, 24, 28, 48, 52, 67, 72, 87, 96 and 110 hours), a magnet $(0.3 \mathrm{~T})$ was placed to the side wall of the vial and it was kept for 1 hour, the time needed to collect all the beads at the magnet. The supernatant was then recovered and the emission spectrum was recorded on it. The amount of released DOXO was determined by a calibration curve obtained by plotting the DOXO adsorption at $483 \mathrm{~nm}$ wavelength versus the DOXO concentration of standard solutions (see ESI, Fig. S1†). After each time step, the DOXO-PNIPAM-NBs re-collected to the magnet were redissolved in $2 \mathrm{~mL}$ of fresh PBS buffer and kept for the additional time lapse before being magnetically separated from the supernatant.

\section{Cell culture and cell viability assay}

$\mathrm{KB}$ cells were grown at $37{ }^{\circ} \mathrm{C}$ and under $5 \% \mathrm{CO}_{2}$ atmosphere in RPMI-1640 medium, supplemented with L-glutamine (2 mM), penicillin (100 units $\left.\mathrm{mL}^{-1}\right)$, streptomycin $\left(100 \mu \mathrm{g} \mathrm{mL}^{-1}\right)$, and $10 \%$ heat-inactivated fetal bovine serum (FBS).

A viability assay (MTT test) was performed using the 3-(4, 5-dimethyl-2-thiazolyl)-2,5-diphenyl-2H-tetrazolium bromide. In detail, $5 \times 10^{4}$ cells suspended in $1 \mathrm{~mL}$ of medium were seeded 
in each well of a 12 well-plate, and after $24 \mathrm{~h}$ incubation at $37^{\circ} \mathrm{C}$, the medium was replaced with $1 \mathrm{~mL}$ of fresh medium containing the DOXO-loaded PNIPAM-NBs at different Fe/DOXO concentrations $(1.25 / 0.65,1.25 / 1.25,1.25 / 2.5,2.5 / 2.5,5 / 5 \mu \mathrm{g}$ $\mathrm{mL}^{-1}$ ). Cells were kept at $37{ }^{\circ} \mathrm{C}$ for 24,48 or $72 \mathrm{~h}$. Then the medium was removed, the cells were washed three times with PBS, and $1 \mathrm{~mL}$ of fresh serum-free medium containing $1 \mathrm{mg}$ $\mathrm{mL}^{-1}$ of MTT was added into each well. After 3 hours of incubation at $37{ }^{\circ} \mathrm{C}$ the medium was removed and the precipitated dark crystals were dissolved in $2 \mathrm{~mL}$ of DMSO, leading to a violet solution whose absorbance at $570 \mathrm{~nm}$ was determined. Each assay was performed in triplicate and with or without the application of a static magnetic field $(0.2 \mathrm{~T})$ under the cell plates. The cytotoxicity of the free DOXO, of the unloaded PNIPAMNBs and of the starting NBs at the same concentrations used for the DOXO experiment was also assayed.

\section{Determination of the intracellular Fe concentration}

To estimate the intracellular $\mathrm{Fe}$ concentration, $10^{5}$ cells suspended in $2 \mathrm{~mL}$ of medium were seeded in each well of a 6 wellplate. After $24 \mathrm{~h}$ incubation at $37^{\circ} \mathrm{C}$ in each well, the medium was replaced with $2 \mathrm{~mL}$ of fresh medium containing either the unloaded PNIPAM-NBs or the starting NBs at a Fe concentration equal to $2.5 \mu \mathrm{g} \mathrm{mL}{ }^{-1}$. Cells were incubated at $37^{\circ} \mathrm{C}$ for 24,48 or 72 hours with or without the application of the magnetic field. Thereafter, the medium was removed; the cells were washed twice with PBS and trypsinized by addition of $500 \mu \mathrm{L}$ of trypsin per well. After $5 \mathrm{~min}$ incubation at $37^{\circ} \mathrm{C}$, the cell suspension was collected and $1.5 \mathrm{~mL}$ of PBS was added in order to recover any remaining cells from each well. The suspension was then centrifuged, the supernatant removed and $2 \mathrm{~mL}$ of a concentrated $\mathrm{HCl}$ solution was added to digest the cells (the solution was left for 48 hours). The intracellular Fe concentration was measured by means of elemental analysis (ICP-OES spectrometer, iCAP 6500, Thermo).

\section{Preparation of cell samples for TEM characterization}

$4 \times 10^{5}$ cells suspended in $8 \mathrm{~mL}$ of medium were seeded in a culture dish. After $24 \mathrm{~h}$ incubation at $37^{\circ} \mathrm{C}$ the medium was replaced with $8 \mathrm{~mL}$ of fresh medium containing either the unloaded PNIPAM beads or the starting beads at a Fe concentration equal to $2.5 \mu \mathrm{g}$ $\mathrm{mL}^{-1}$. Cells were incubated at $37^{\circ} \mathrm{C}$ for 24,48 or $72 \mathrm{~h}$. Then, they were washed with PBS and fixed with $2.5 \%$ glutaraldehyde in $0.1 \mathrm{M}$ cacodylate buffer at $4{ }^{\circ} \mathrm{C}$ for $30 \mathrm{~min}$. The fixed specimens were washed three times with the same buffer and $1 \%$ osmium tetroxide in cacodylate buffer was added for $1 \mathrm{~h}$. Thereafter, the cells were washed again and dehydrated with $25 \%, 50 \%, 75 \%$ and $100 \%$ acetone. Two steps of infiltration in a mixture of resin/ acetone (1/1 and $2 / 1$ ratios) followed and finally the specimens were embedded in $100 \%$ resin at $60{ }^{\circ} \mathrm{C}$ for $48 \mathrm{~h}$. Ultrathin sections (100 $\mathrm{nm}$ thick) were cut on an Ultramicrotome (Leika), stained with lead citrate and observed under a JEOL JEM-1011 microscope operating at $100 \mathrm{kV}$.

\section{Instruments used}

$\zeta$-Potential and dynamic light measurements (DLS) were performed on a Zetasizer Nano ZS90 (Malvern, USA) equipped with a $4.0 \mathrm{~mW} \mathrm{He}-\mathrm{Ne}$ laser operating at $633 \mathrm{~nm}$ and an avalanche photodiode detector. Measurements were made at $25{ }^{\circ} \mathrm{C}$ in deionized water. All the samples were filtered using $0.45 \mu \mathrm{m}$ filters before analysis. DLS measurements were made at temperatures ranging from 20 to $55^{\circ} \mathrm{C}$ at a temperature interval of $3{ }^{\circ} \mathrm{C}$, allowing temperature stabilization for a period of 15 minutes before each measurement. For the experiments, the concentration of NBs samples (the starting NBs and the PNIPAM-NBs) was of $5 \mu \mathrm{g} \mathrm{mL}{ }^{-1} \mathrm{Fe}$. The UV-visible absorption spectra were measured using a Varian Cary 300 UV-Vis spectrophotometer while the Photoluminescence (PL) spectra were recorded on a Cary Eclipse spectrophotometer. The FT-IR measurements were recorded on Bruker vertex V80 FT-IR spectrometer. The TEM images were recorded on a JEOL jem 1011 microscope operated at an accelerating voltage of $100 \mathrm{kV}$. TEM samples of the bare materials were prepared by dropping a diluted solution of nanobeads in water on carbon-coated copper grids and letting the solvent evaporate. Confocal microscopy images of living KB cells incubated with the DOXOPNIPAM-NBs were recorded on a Nikon Eclipse Ti microscope equipped with an argon laser source (excitation at $488 \mathrm{~nm}$ ). Images were recorded at time $0,2,7$ and $15 \mathrm{~h}$ using an acquisition window set at $590 \pm 20 \mathrm{~nm}$. For the image of fixed cells, the cells previously incubated for 15 hours at $37{ }^{\circ} \mathrm{C}$ with DOXO-PNIPAM-NBs were washed with PBS, fixed with $4 \%$ PBS buffered paraformaldehyde, and the nuclei stained with 4'-6-diamidino-2phenylindole (DAPI). The specimens were observed under the confocal microscope, using two laser excitation sources (at 405 and $488 \mathrm{~nm}$ ), and two acquisition channels at $450 \pm 20 \mathrm{~nm}$ and $590 \pm 20 \mathrm{~nm}$ respectively, for DAPI and DOXO.

\section{Acknowledgements}

This work was supported in part by the European project Magnifyco (Contract NMP4-SL-2009-228622). We thank Mario Malerba for TEM sample preparation and Dr Liberato Manna for helpful discussion.

\section{References}

1 M. Das, H. Zhang and E. Kumacheva, Annu. Rev. Mater. Res., 2006, 36, 117-142.

2 N. A. Peppas, J. Z. Hilt, A. Khademhosseini and R. Langer, $A d v$. Mater., 2006, 18, 1345-1360.

3 A. Chilkoti, M. R. Dreher, D. E. Meyer and D. Raucher, Adv. Drug Delivery Rev., 2002, 54, 613-630.

4 S. Ganta, H. Devalapally, A. Shahiwala and M. Amiji, J. Controlled Release, 2008, 126, 187-204.

5 D. Schmaljohann, Adv. Drug Delivery Rev., 2006, 58, 1655-1670.

6 K. Raemdonck, J. Demeester and S. De Smedt, Soft Matter, 2009, 5, 707-715.

7 T. Y. Liu, S. H. Hu, D. M. Liu, S. Y. Chen and I. W. Chen, Nano Today, 2009, 4, 52-65.

8 A. Figuerola, R. Di Corato, L. Manna and T. Pellegrino, Pharmacol. Res., 2010, 62, 126-143.

9 F. Gazeau, M. Levy and C. Wilhelm, Nanomedicine, 2008, 3, 831-844.

10 A. H. Lu, E. L. Salabas and F. Schuth, Angew. Chem., Int. Ed., 2007, 46, 1222-1244.

11 S. R. Deka, A. Quarta, R. Di Corato, A. Falqui, L. Manna, R. Cingolani and T. Pellegrino, Langmuir, 2010, 26, 10315-10324.

12 A. M. Schmidt, Colloid Polym. Sci., 2007, 285, 953-966.

13 Y. H. Lien and T. M. Wu, J. Colloid Interface Sci., 2008, 326, 517-521.

14 N. S. Satarkar, D. Biswal and J. Z. Hilt, Soft Matter, 2010, 6, 2364 2371. 
15 A. Sánchez-Iglesias, M. Grzelczak, B. Rodríguez-Gonzaález, P. Guardia-Girós, I. Pastoriza-Santos, J. Pérez-Juste, M. Prato and L. M. Liz-Marzán, ACS Nano, 2009, 3, 3184-3190.

16 J. Rubio-Retama, N. E. Zafeiropoulos, C. Serafinelli, R. RojasReyna, B. Voit, E. Lopez Cabarcos and M. Stamm, Langmuir, 2007, 23, 10280-10285.

17 L. B. Chen, F. Zhang and C. C. Wang, Small, 2009, 5, 621-628.

18 H. G. Schild, Prog. Polym. Sci., 1992, 17, 163-249.

19 Y. Maeda, T. Higuchi and I. Ikeda, Langmuir, 2000, 16, 7503-7509.

20 A. P. Herrera, M. Rodriguez, M. Torres-Lugo and C. Rinaldi, $J$. Mater. Chem., 2008, 18, 855-858.

21 J. Qin, Y. S. Jo and M. Muhammed, Angew. Chem., Int. Ed., 2009, 48, 7845-7849.

22 D. L. LesliePelecky and R. D. Rieke, Chem. Mater., 1996, 8, 1770-1783.

23 A. G. Roca, M. P. Morales, K. O'Grady and C. J. Serna, Nanotechnology, 2006, 17, 2783-2788.

24 Y. B. Sun, X. B. Ding, Z. H. Zheng, X. Cheng, X. H. Hu and Y. X. Peng, Chem. Commun., 2006, 2765-2767.

25 M. Rahimi, A. Wadajakar, K. Subramanian, M. Yousef, W. Cui, J. T. Hsieh and K. T. Nguyen, Nanomedicine, 2010, 6, 672-680.

26 M. Arruebo, R. Fernández-Pacheco, M. R. Ibarra and J. Santamaría, Nano Today, 2007, 2, 22.

27 R. Di Corato, P. Piacenza, M. Musaro, R. Buonsanti, P. D. Cozzoli, M. Zambianchi, G. Barbarella, R. Cingolani, L. Manna and T. Pellegrino, Macromol. Biosci., 2009, 9, 952-958.

28 D. Suzuki and H. Kawaguchi, Colloid Polym. Sci., 2006, 284, 14431451.

29 T. Kawano, Y. Niidome, T. Mori, Y. Katayama and T. Niidome, Bioconjugate Chem., 2009, 20, 209-212.

30 M. Ballauff and Y. Lu, Polymer, 2007, 48, 1815-1823.

31 R. Contreras-Caceres, A. Sanchez-Iglesias, M. Karg, I. PastorizaSantos, J. Perez-Juste, J. Pacifico, T. Hellweg, A. FernandezBarbero and L. M. Liz-Marzan, Adv. Mater., 2008, 20, 1666-1670.

32 H. Vihola, A. Laukkanen, L. Valtola, H. Tenhu and J. Hirvonen, Biomaterials, 2005, 26, 3055-3064.
33 D. Peer, J. M. Karp, S. Hong, O. C. FaroKhzad, R. Margalit and R. Langer, Nat. Nanotechnol., 2007, 2, 751-760.

34 L. Wang and J. Q. Sun, J. Mater. Chem., 2008, 18, 4042-4049.

35 T. Minko, S. S. Dharap, R. I. Pakunlu and Y. Wang, Curr. Drug Targets, 2004, 5, 389-406.

36 G. Szakacs, J. K. Paterson, J. A. Ludwig, C. Booth-Genthe and M. M. Gottesman, Nat. Rev. Drug Discovery, 2006, 5, 219 234.

37 M. Susa, A. K. Iyer, K. Ryu, F. J. Hornicek, H. Mankin, M. M. Amiji and Z. F. Duan, BMC Cancer, 2009, 9, 12.

38 E. Munnier, S. Cohen-Jonathan, C. Linassier, L. Douziech-Eyrolles, H. Marchais, M. Souce, K. Herve, P. Dubois and I. Chourpa, Int. J. Pharm., 2008, 363, 170-176.

39 J. W. Liu, Y. Zhang, C. Y. Wang, R. Z. Xu, Z. P. Chen and N. Gu, J. Phys. Chem. C, 2010, 114, 7673-7679.

40 J. S. Guthi, S. G. Yang, G. Huang, S. Z. Li, C. Khemtong, C. W. Kessinger, M. Peyton, J. D. Minna, K. C. Brown and J. M. Gao, Mol. Pharmaceutics, 2010, 7, 32-40.

41 J. E. Lee, N. Lee, H. Kim, J. Kim, S. H. Choi, J. H. Kim, T. Kim, I. C. Song, S. P. Park, W. K. Moon and T. Hyeon, J. Am. Chem. Soc., 2010, 132, 552-557.

42 G. B. Hong, R. X. Yuan, B. L. Liang, J. Shen, X. Q. Yang and X. T. Shuai, Biomed. Microdevices, 2008, 10, 693-700.

43 R. R. Arvizo, O. R. Miranda, M. A. Thompson, C. M. Pabelick, R. Bhattacharya, J. D. Robertson, V. M. Rotello, Y. S. Prakash and P. Mukherjee, Nano Lett., 2010, 10, 2543-2548.

44 M. Liang, I. C. Lin, M. R. Whittaker, R. F. Minchin, M. J. Monteiro and I. Toth, ACS Nano, 2010, 4, 403-413.

45 M. J. Tiera, G. R. dos Santos, V. A. D. Tiera, N. A. B. Vieira, E. Frolini, R. C. da Silva and W. Loh, Colloid Polym. Sci., 2005, 283, 662-670.

46 A. Zintchenko, M. Ogris and E. Wagner, Bioconjugate Chem., 2006, 17, 766-772.

47 D. E. Meyer, B. C. Shin, G. A. Kong, M. W. Dewhirst and A. Chilkoti, J. Controlled Release, 2001, 74, 213-224. 